\title{
Selection and treatment of patients for transcatheter aortic valve implantation through a day hospital: a case report
}

\author{
(D) Matija Vrbanićc ${ }^{*}$, \\ (D) Kristijana Radić', \\ (DIvica Benko1,2, \\ (DLjiljana Švađumovićc', \\ (D) Vlatka Funduk 1 , \\ (DBiljana Šego', \\ (D) Mirjana Slanc', \\ (D) Mirela Adamovićć, \\ (D)Zoran Marić1, \\ (D)Ivana Jelinek ${ }^{1}$ \\ 'University Hospital Dubrava, \\ Zagreb, Croatia \\ 2University of Applied Health \\ Sciences, Zagreb, Croatia
}

RECEIVED:

September 7, 2021

ACCEPTED:

September 14, 2021

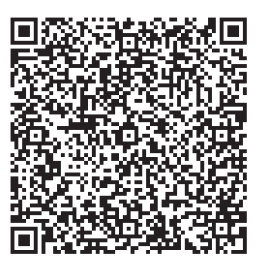

$\square$ Cardiologia Croatica 2021;16(11-12):366.

\begin{abstract}
KEYWORDS: severe aortic stenosis, transcatheter aortic valve implantation, day hospital. CITATION: Cardiol Croat. 2021;16(11-12):366. | https://doi.org/10.15836/ccar2021.366

*ADDRESS FOR CORRESPONDENCE: Matija Vrbanić, Klinička bolnica Dubrava, Avenija Gojka Šuška 6, HR-10000 Zagreb, Croatia / Phone +385-1-290-2545 / E-mail: matija.vrbanic23@gmail.com

ORCID: Matija Vrbanić, https://orcid.org/0000-0002-3229-9436 • Kristijana Radić, https://orcid.org/0000-0002-6098-254X Ivica Benko, https://orcid.org/0000-0002-1878-0880 • Ljiljana Švađumović, https://orcid.org/0000-0002-9068-2716 Vlatka Funduk, https://orcid.org/0000-0001-7070-188x • Biljana Šego, https://orcid.org/0000-0002-0806-1233 Mirjana Slanc, https://orcid.org/0000-0002-6247-4696 • Mirela Adamović, https://orcid.org/0000-0003-4922-7436 Zoran Marić, https://orcid.org/0000-0002-9121-4631 • Ivana Jelinek, https://orcid.org/0000-0003-4315-888x
\end{abstract}

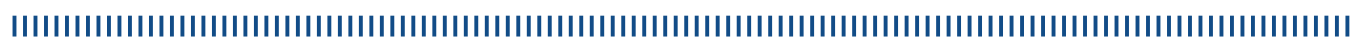

Severe aortic stenosis is becoming an increasingly common disease in an increasing number of patients older than 75 years. In addition to patients with severe comorbidities and high or prohibited surgical risk for treatment of severe aortic stenosis, these patients could be candidates for TAVI (transcatheter aortic valve implantation). ${ }^{1,2}$ With the increase in the number of candidates for TAVI in Croatia in the last 2 years, we can see a trend of a significant increase in the number of procedures, and during 2020 for the first time in Croatia, more than 200 procedures were performed in one year, reaching the minimum European average. In recent years, emphasis has been placed on minimally invasive, "accelerated" procedures for the treatment of these patients, with the least need for treatment in the intensive care unit and the shortest possible hospital stay. The COVID-19 pandemic has further increased the need for as few hospitalizations as possible and as short hospital stays as possible, so an increase in the number of TAVI candidates is expected in the future.

Here we show the role of the staff at the day hospital and the cardiology department in the fastest and most accurate selection and treatment of patients for TAVI, to short hospital treatment, with as few complications and a short stay at intensive care units. This report shows the role of the day hospital in rapid processing and selection of treatment strategy as also a vascular approach, to reduce the possibility of complications during the stay at the ward, as well as in the invasive cardiology laboratory, and subsequent monitoring of treatment outcomes and long-term success.
LITERATURE IIIIIIIIIIIIIIIIIIIIIIIIIIIIIIIIIIIIIIIIIIIIIIIIIIIIIIIIIIIIIIIIIIIIIIIIIIIIIIIIIIIIIIIIIIIIIIIIIIIIIIIII

1. Durko AP, Osnabrugge RL, Van Mieghem NM, Milojevic M, Mylotte D, Nkomo VT, et al. Annual number of candidates for transcatheter aortic valve implantation per country: current estimates and future projections. Eur Heart J. 2018 Jul 21;39(28):2635-2642. https://doi.org/10.1093/eurheartj/ehy107

2. Hadžibegović I, Unić D, Jurin I, Bradić N, Starčević B, Rudež I. Percutaneous transfemoral approach and additional vascular access selection influence hospital stay and survival after transcatheter aortic valve implantation. Cardiol Croat. 2021;16(1-2):36. https://doi.org/10.15836/ccar2021.36 